Research Article

\title{
Reactivation of Ancient Landslide Deposits: Geological Characteristics and Deformation Mechanism
}

\author{
Rubin Wang $\mathbb{D}^{1,2}$ Kun Zhang, ${ }^{2}$ Yu Ning, ${ }^{3}$ Weiya Xu $\mathbb{D},{ }^{2}$ Wenyuan Wang, ${ }^{3}$ and Jianfu Qin ${ }^{3}$ \\ ${ }^{1}$ Key Laboratory of Ministry of Education for Geomechanics and Embankment Engineering, Hohai University, \\ Nanjing 210098, China \\ ${ }^{2}$ Research Institute of Geotechnical Engineering, Hohai University, Nanjing 210098, China \\ ${ }^{3}$ Kunming Engineering Corporation Limited, PowerChina, Kunming 650051, China \\ Correspondence should be addressed to Rubin Wang; rbwang@hhu.edu.cn
}

Received 18 December 2020; Accepted 13 May 2021; Published 24 May 2021

Academic Editor: Xingzhou Chen

Copyright (c) 2021 Rubin Wang et al. This is an open access article distributed under the Creative Commons Attribution License, which permits unrestricted use, distribution, and reproduction in any medium, provided the original work is properly cited.

\begin{abstract}
The ancient Zhenggang landslide $\left(47.5\right.$ million $\left.\mathrm{m}^{3}\right)$ represents a potential threat to the construction and safe operation of the proposed Gushui Hydropower Project and to the people living downstream. The landslide was caused by continuous rainfall from October 20 to November 5, 2008, indicating that groundwater aggravated sliding and deformation, and it can be divided into two distinct zones: zone I and zone II. Investigations of the Zhenggang landslide deposits have been conducted for 10 years, but the evolution of the landslide deformation is yet to be revealed. Geological surveys and stability analysis have revealed that the Zhenggang landslide is currently relatively stable and is not sliding. The deformational data for the deep soil layers show that subslide zone I is a translational slide, while subslide zone II is an uplift slide, and zone II is slightly more stable than zone I. Obvious interior deformational failure occurred and was observed in the exploratory adits. The numerical results show that rainfall infiltration is the main factor to induce the revival of ancient landslide, and it is necessary to strengthen the landslide risk assessment and reliability of Zhenggang landslide under the condition of rainfall infiltration. Finally, in order to reduce landslide risks, the local residents living near the landslide mass should be relocated, and measures should be taken to increase slope stability.
\end{abstract}

\section{Introduction}

Landslides in mountainous areas can have major adverse impacts on rivers, reservoirs, and humans living downstream. They can obstruct river catchments $[1,2]$, create landslide dams [3, 4], and damage reservoirs. Landslides can produce huge landslide-dammed lakes in river channels and produce destructive impulse waves [5] in reservoirs that can have disastrous effects on the downstream inhabitants. Tragedies resulting from landslide dams occurred in 1786 on the Dadu River, Sichuan, China [6], and in 1963 on the Vajont reservoir, near Venice, Italy [7]. These disasters resulted in about 100,000 and 2,600 casualties, respectively.

Examples of landslide dams and reservoir slope failures have been reported in many parts of the world [8-12]. Although they occurred in different locations, the compositions of these landslides have a common characteristic: they mainly consist of detritus, soils, and gravels. Landslides are caused by several factors, including texture, topography, the geological properties of slopes, precipitation, and seismic activity $[6,12-14]$. The trigger of the primary failure differs among landslides, but the geomaterials of most riverside landslides have low strengths [15-17]. This stems from their geological evolution. Rock masses in mountainous areas are often broken into smaller stones, debris particles, and soils due to weathering. Deposits of unconsolidated geomaterials with large voids are fragile and move relatively easily when slope failure is triggered.

Slope failures near rivers and reservoirs are common in China, especially in the mountainous areas of southwestern China, where the geological environments are unstable. Giant landslides often occur in this region and threaten 
rivers, reservoirs, and human lives [18]. In recent years, substantial research has been conducted on slope failure $[19,20]$, especially in regions near large rivers such as the Jinsha, Minjiang, and Yangtze rivers. These studies have focused on identification, statistical surveys, analysis of the spatial distributions of landslides, and impact assessments. The hydropower resources provided by large rivers are an important component of China's energy plan, and there are many large-scale hydropower projects that are either completed or under construction on these rivers. These projects and downstream riparian inhabitants are threatened by potentially destructive landslides. Identification, geological study, stability analysis, and safety evaluation of the landslides close to these rivers and reservoirs are needed to maximize the safe construction and operation of dams and reservoirs.

Most of the research on landslides in southwestern China has focused on landslide identification, statistical surveys, and spatial distributions. Geological evaluation, sliding mechanisms, field investigations, physical-mechanical experiments on slip soils, and parameter determination have been less well studied. In consideration of the geological diversity and complexity, a case study of a landslide can provide valuable insight into the factors that predispose regions to these Earth movements. The Zhenggang landslide is a potential threat to the Gushui Hydropower Project. If the landslide slope fails and slides into the river, the river channel will potentially be blocked and form a large landslide-dammed lake, which will pose a significant risk to the downstream inhabitants. Therefore, a potential landslide is a serious concern. Thus, it is important to study the geological characteristics and resurrection mechanisms of the Zhenggang landslide in order to reveal the evolution process and prevent and control the landslide.

\section{Geological Characteristics of the Landslide Area}

2.1. Geoenvironmental Conditions. The Zhenggang landslide is located on the southeastern part of the Tibetan Plateau, which is a transitional region between the geological features of Yunnan and Tibet. This landslide occurred on the right bank (looking downstream) of the river channel, about $1 \mathrm{~km}$ downstream of the Gushui Hydropower Project, which is located on the upper reaches of the Lancang River, Deqin County, northwestern Yunnan Province, China (Figure 1). This area is a convergence region of four tectonic units: the Gangdese-Nyainqentanglha Geosynclinal fold system to the west, the Tanggulha-Qamdo-Lanping-Simao Geosynclinal fold system, the Songpan-Ganzi Geosynclinal fold system, and the Yangtze Craton to the east, and it is part of a tectonically active mountainous region.

The study area has a monsoon climate characterized by low temperatures, low rainfall, low humidity, large evaporation, and a long frost period. The range of annual rainfall is $494.7-522.4 \mathrm{~mm}$. The vegetation is sparse along the banks of the Lancang River in the study area. Fragile ecological environments and complicated geomorphological and geological conditions make this area susceptible to frequent geological disasters, especially catastrophic landslides, as well as the possible extinction of rare animals and plants. The hydrogeology is relatively simple, and the groundwater can be classified into two types: fissure water and porous water. The main sources of groundwater are melting snow and ice and atmospheric precipitation. The ice and snow melt water provides a steady and abundant water supply. The slip zone is relatively impermeable, and water accumulates in the landslide mass. Spring water levels are relatively high, and several spring water outlets were discovered during the site investigation.

\subsection{Spatial Morphology and Zoning Characteristics of the} Landslide. The planar morphology and regional characteristics of the Zhenggang landslide are shown in Figure 2. A recent survey reported that the formation history of the Zhenggang landslide deposit can be divided into four eons. From oldest to newest, these formation periods were the third terrace, outwash deposits, old landslide, and reconstruction period of the later landslide deposits. The earliest formation period of the bedrock slide occurred more than 7,500 years ago. The landslide has a total volume of $4.75 \times 107 \mathrm{~m}^{3}$ and an area of $1.70 \times 10^{6} \mathrm{~m}^{2}$ (Figures 2 and 3 ), is located at an elevation of 2180 to $3220 \mathrm{~m}$, is $1300 \mathrm{~m}$ wide, and is $28.8 \mathrm{~m}$ thick (range $=15-85 \mathrm{~m}$ ). This landslide originated from a large-scale rock slide that experienced subsequent sliding. Its rear edge outcrops at 3010-3700 m, with a slope of $46^{\circ}$. It is tongue-shaped in plain view and armchair-shaped at its rear part, while the elevation of its front $(2180-2250 \mathrm{~m})$ is forward convex and arc-shaped.

The landslide is divided into two sections by the Zhenggang gully. The left part of the landslide is defined as subslide zone I, which has an approximate volume of $9.4 \times 10^{6} \mathrm{~m}^{3}$. The right part is defined as subslide zone II, which has an approximate volume of $3.81 \times 10^{7} \mathrm{~m}^{3}$. Zones I and II have experienced two sliding deformations, which formed the second-stage and third-stage landslides. New landslide deformation zones created by the influence of rainfall and human activity have been recently discovered, with a total volume of $4.75 \times 10^{7} \mathrm{~m}^{3}$. This deformation portion accounts for $60.9 \%\left(2.89 \times 10^{7} \mathrm{~m}^{3}\right)$, of which $5.46 \times 10^{6} \mathrm{~m}^{3}$ is located in zone $\mathrm{I}$, and the remaining $2.35 \times 10^{7} \mathrm{~m}^{3}$ is located in zone II.

Landslide deformation is mainly observed between the Yagong gully and the Right No. 7 gully. Its upstream boundary is located at Right No. 7 gully, at $2200-2450 \mathrm{~m}$ and trending approximately $5^{\circ} \mathrm{S}-20^{\circ} \mathrm{W}$ above $2450 \mathrm{~m}$. The downstream boundary is in Yagong gully, at 2200-2500 m and trending approximately $\mathrm{N} 30^{\circ} \mathrm{E}$. The topological information indicates that the terrain integrity and slope angles of the landslide vary with elevation and can be divided into three types. Above $2750 \mathrm{~m}$, the terrain is intact and steep, with slope angles ranging from $30^{\circ}$ to $50^{\circ}$. Between $2250 \mathrm{~m}$ and $2750 \mathrm{~m}$, the slope is gentler (slope angles ranging from $20^{\circ}$ to $30^{\circ}$ ), and this area has been used by local villagers for several hundred years. Below $2250 \mathrm{~m}$, the landslide terrain worsens, and the slope is precipitous, with a slope angle of about $40^{\circ}$, which is primarily due to erosion of the gullies and 

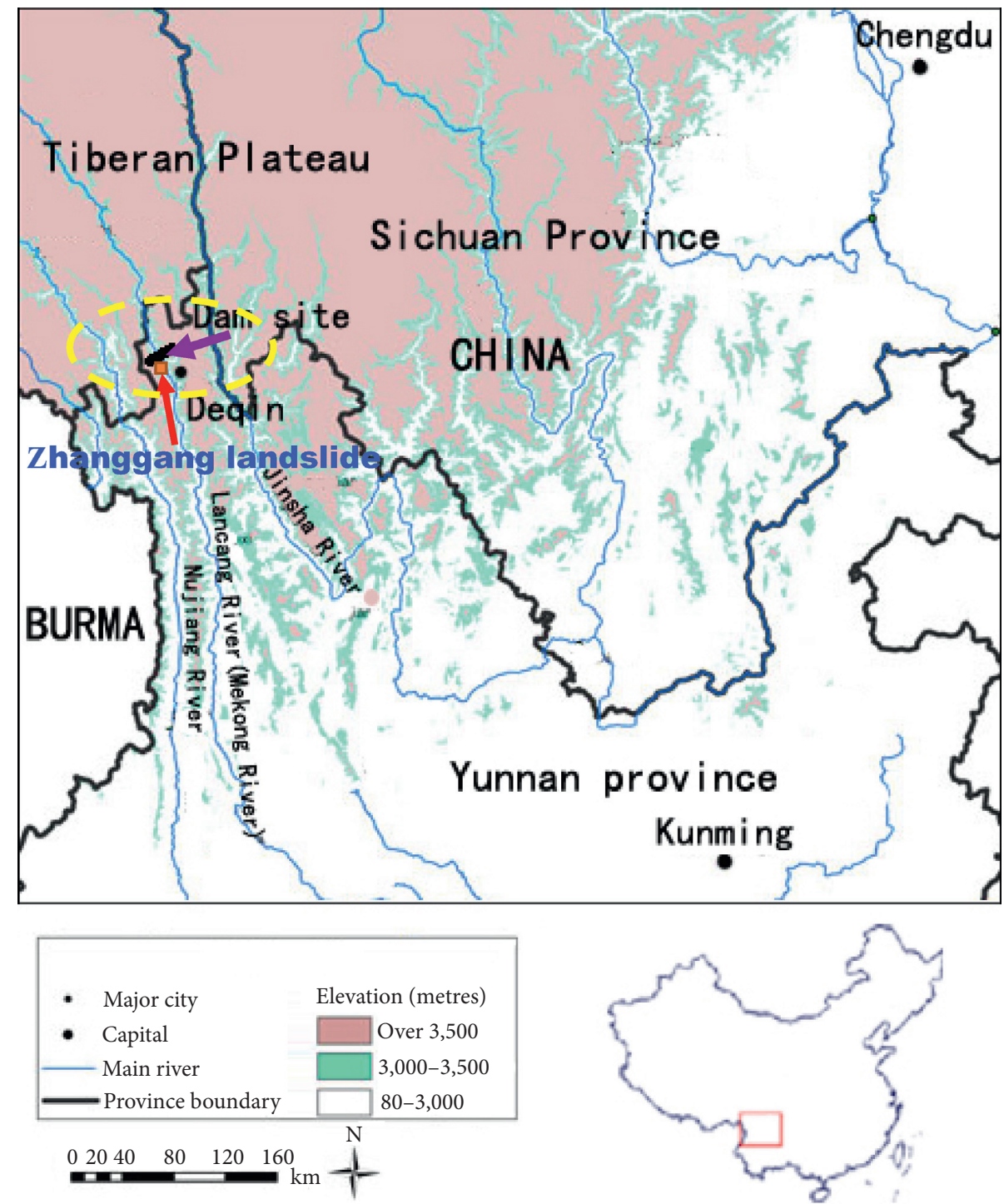

Figure 1: Location of the Zhenggang landslide near the Gushui Hydropower Project.

the Lancang River. Bedrock outcrops occur below $2200 \mathrm{~m}$. There are two small villages (Yagong and Zhenggang) located on the flat terraces. The landslide is a threat to the hydroelectric dam project and to the local villagers living in the area.

2.3. Composition and Structural Characteristics of the Landslide Mass. Two geological profiles of the Zhenggang landslide, profiles A-A' and B-B', are shown in Figure 4. Their schematic locations are shown in Figures 2 and 3. Profile A-A' is a typical geologic section of zone I, and profile $\mathrm{B}-\mathrm{B}$ ' is a typical geologic section of zone II. Tectonically, the landslide region is a monocline with a stratigraphic attitude of $\mathrm{N} 20-30^{\circ}, \mathrm{SW} \angle 65-85^{\circ}$. In more recent geological periods, as a result of rock strata toppling deformation, the stratigraphic attitude near the slope surface changed to N30 $-35^{\circ}$, SW $\angle 15-30^{\circ}$. The depth of the toppling extended to $100 \mathrm{~m}$ beneath the slope. At a horizontal depth of $54 \mathrm{~m}$ in EA-203, a slip zone and fractured slate can be observed.
The weathered rock mass, which is an unfavorable geological feature of this region, was formed by extended tectonic activities, unloading, toppling deformation, and quaternary glaciation. The ruptured structural planes of the rock mass are more developed in this region. Except for the regional and zonal faults, the secondary structural surfaces are also considerably well developed in the form of compression fractures.

The geological surveys and the information shown in Figure 4 show that the major lithological formations are alluvium deposits $\left(\mathrm{Q}^{\mathrm{dl}}\right)$, frozen glaciofluvial deposits $\left(\mathrm{Q}^{\mathrm{fgl}}\right)$, and diluvium deposits $\left(\mathrm{Q}^{\mathrm{del}}\right)$. The bedrock underlying the deposits is composed of the Lower Permian Jidonglong Formation $\left(\mathrm{P}_{1 \mathrm{j}}\right)$, the Upper Triassic Hongpo Formation $\left(\mathrm{T}_{3 \mathrm{hn}}\right)$, and the Hongshan-Gushui Fault $\left(\mathrm{F}_{3}\right)$. The strata differ in composition and characteristics.

2.4. Characteristics of the Sliding Zone. In order to reveal the characteristics of the slide zone, many drill holes and exploration adits have been constructed on the landslide. As 


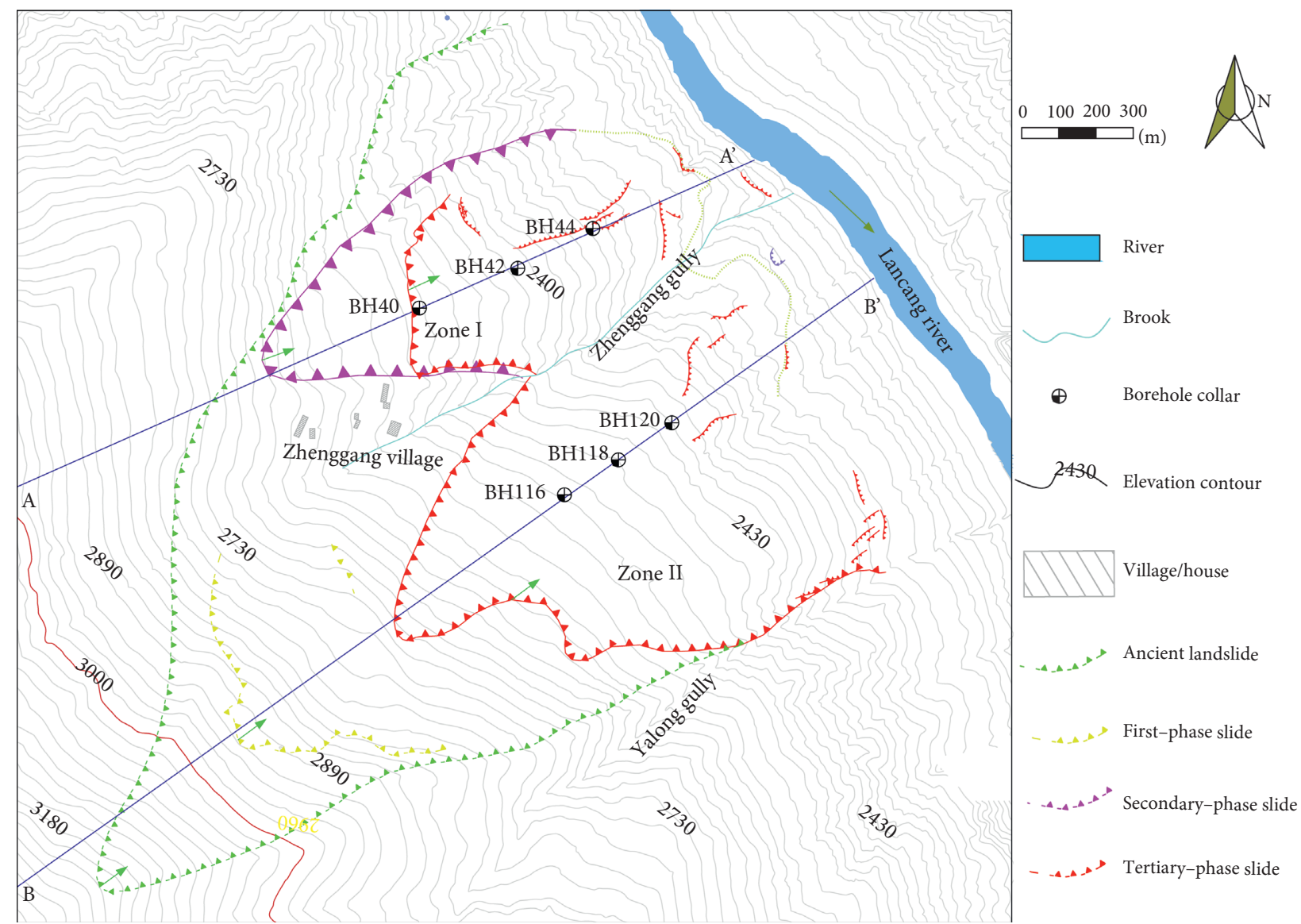

FIgure 2: Planar morphology and regional characteristics of the Zhenggang landslide.

shown in Figure 5, a total of three boreholes and three exploration adits were laid along section A-A'. Five boreholes and five exploration adits were lain along section B-B'.

By analyzing the exploration results, it was found that the variation characteristics of the soil's composition in the longitudinal section of the deep slip zone are obvious, the gravel content in the back of the slide zone is high, the gravel is composed of slate and sandstone, and the material composition is simple and mostly dry. The clay content of the sliding zone soil in the middle of the slide body is high, the soil is mostly plastic, and the material composition tends to be complex. The lithoclastic composition is mainly slate and sandstone, with a small amount of limestone and argillaceous siltstone. The front is characterized by a sliding overburden structure, the gravel content in the sliding overburden zone is high, and the material composition is complex. The composition of the gravel is slate, sandstone, limestone, argillaceous siltstone, and basalt. From the point of view of the material composition of the sliding zone's soil, the strength of the sliding zone's soil in the rear and front parts of the accumulation body is higher, while the strength of the soil in the middle of the sliding zone is lower. The soil of the secondary slide zone is mainly clay, and the gravel content is lower. The longitudinal change in the composition of the gravel is consistent with that of the primary sliding zone of the old landslide. The characteristics of the rear three levels of the sliding zone are obvious, and the secondary sliding zone tracks to the first-stage sliding zone in the middle and front, which is also the manifestation of the low soil strength in the front of the first stage of the sliding zone of the old landslide.

Physical test results in unit weight, and limit water content and particle size analysis are shown in Table 1, while particle size gradation curves for landslide mass soil (LMS) and slip zone soil (SZS) are illustrated in Figure 6. It is interesting to find that although two types of soils have comparatively little difference in unit weight, limit water content and the gap between particle size graduation curves vary greatly with soil components. Due to a large amount of coarse grains, soil of landslide mass has lower limit water contents than slip zone, with less content of $8 \%$ in liquid limit and $3.4 \%$ in plastic limit. Observations about particle size analysis from Figure 6 and Table 1 confirm that waterproof layer, and the water stagnation phenomenon is obvious in the upper layer of the landslide deposits.

\section{Crack Propagation and Collapse Characteristics after Rainfall}

Rain fell at the dam site from October 20 to November 5, 2008, and the heaviest rainfall occurred over a 3-day period. As shown in Figure 7, the total October precipitation in 2008 was $151 \mathrm{~mm}$, with a maximum daily precipitation of $78 \mathrm{~mm}$, which exceeded the maximum record for the Liutongjiang 


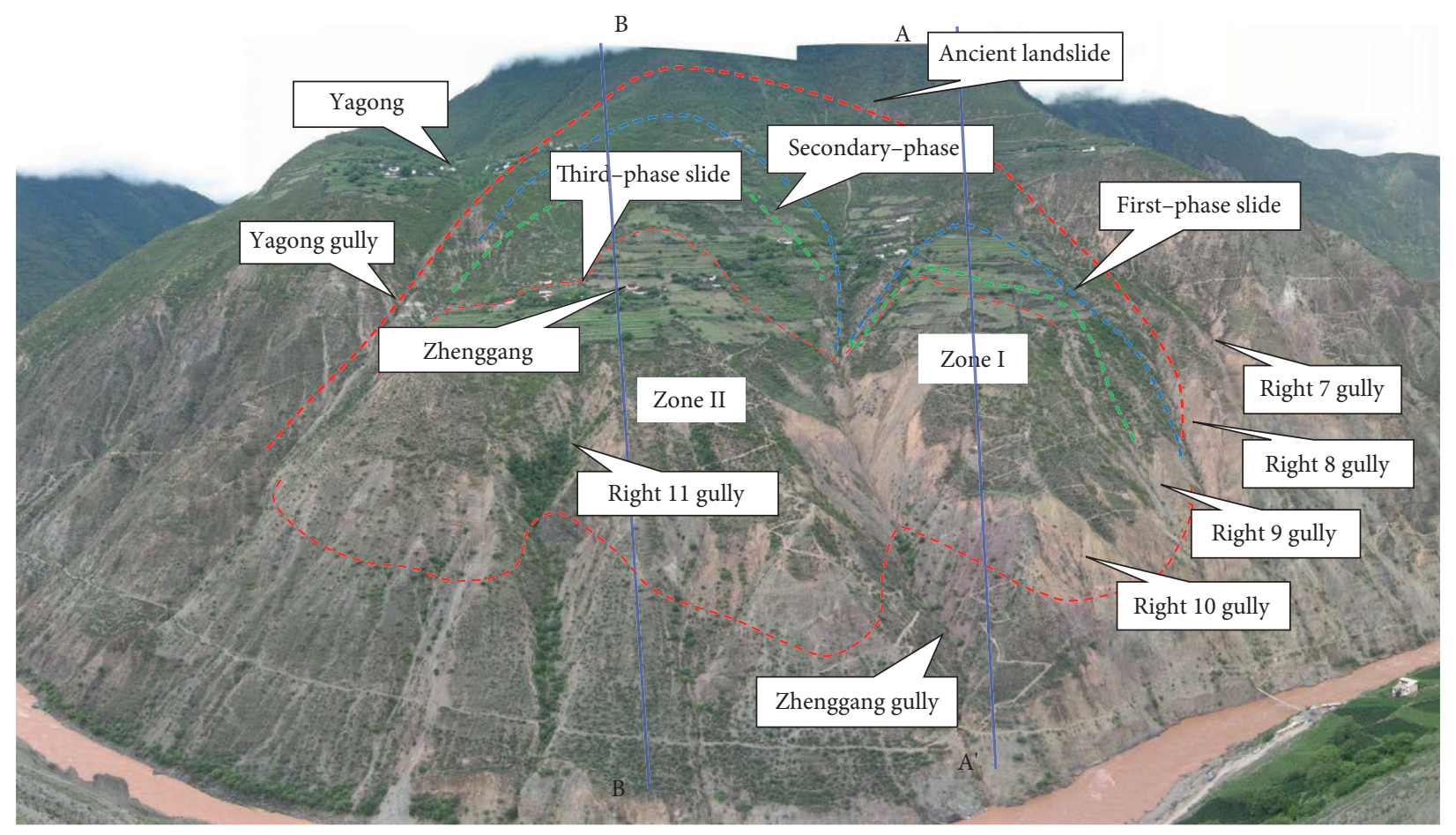

FIgURE 3: Front view of the Zhenggang landslide.

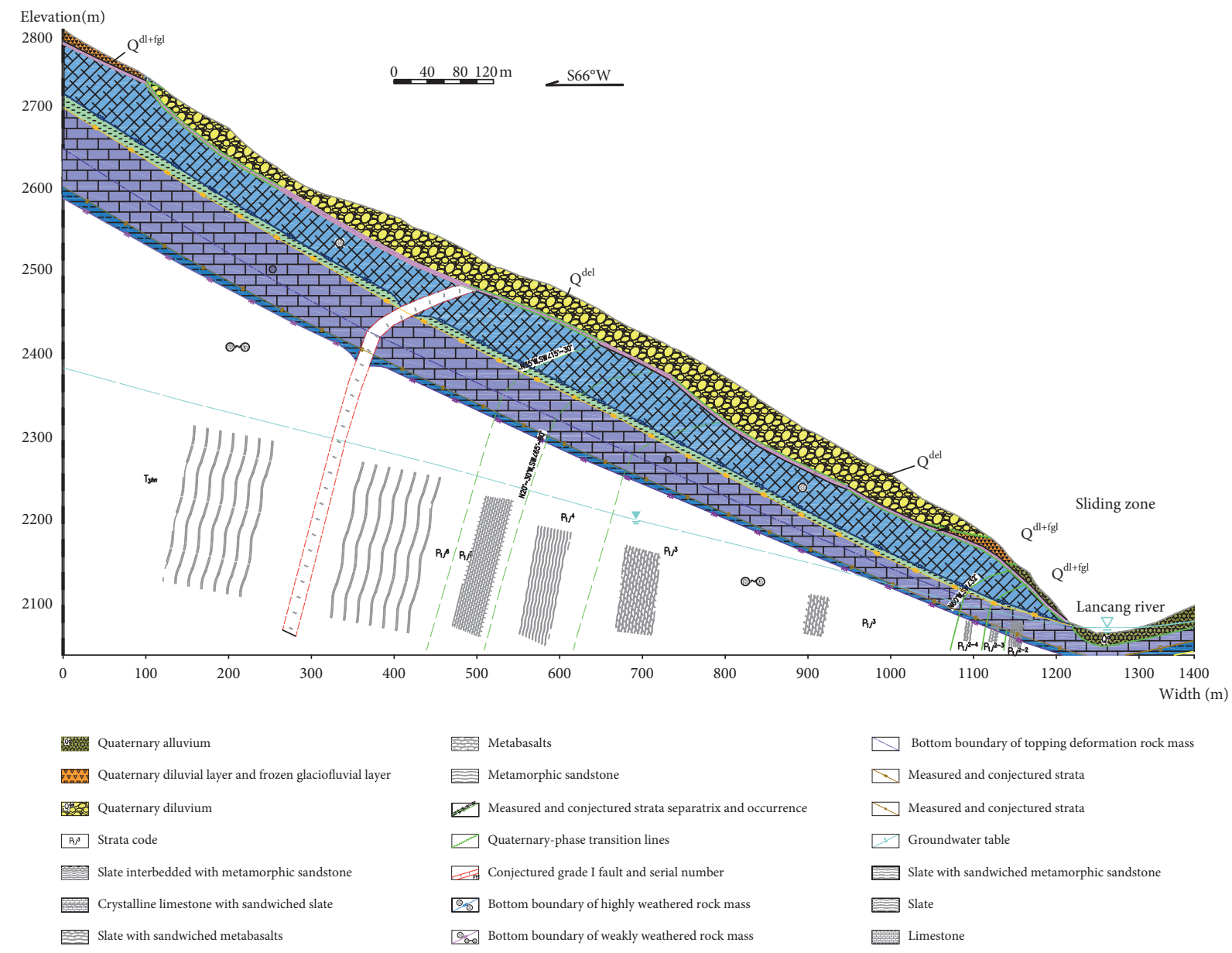

(a)

Figure 4: Continued. 


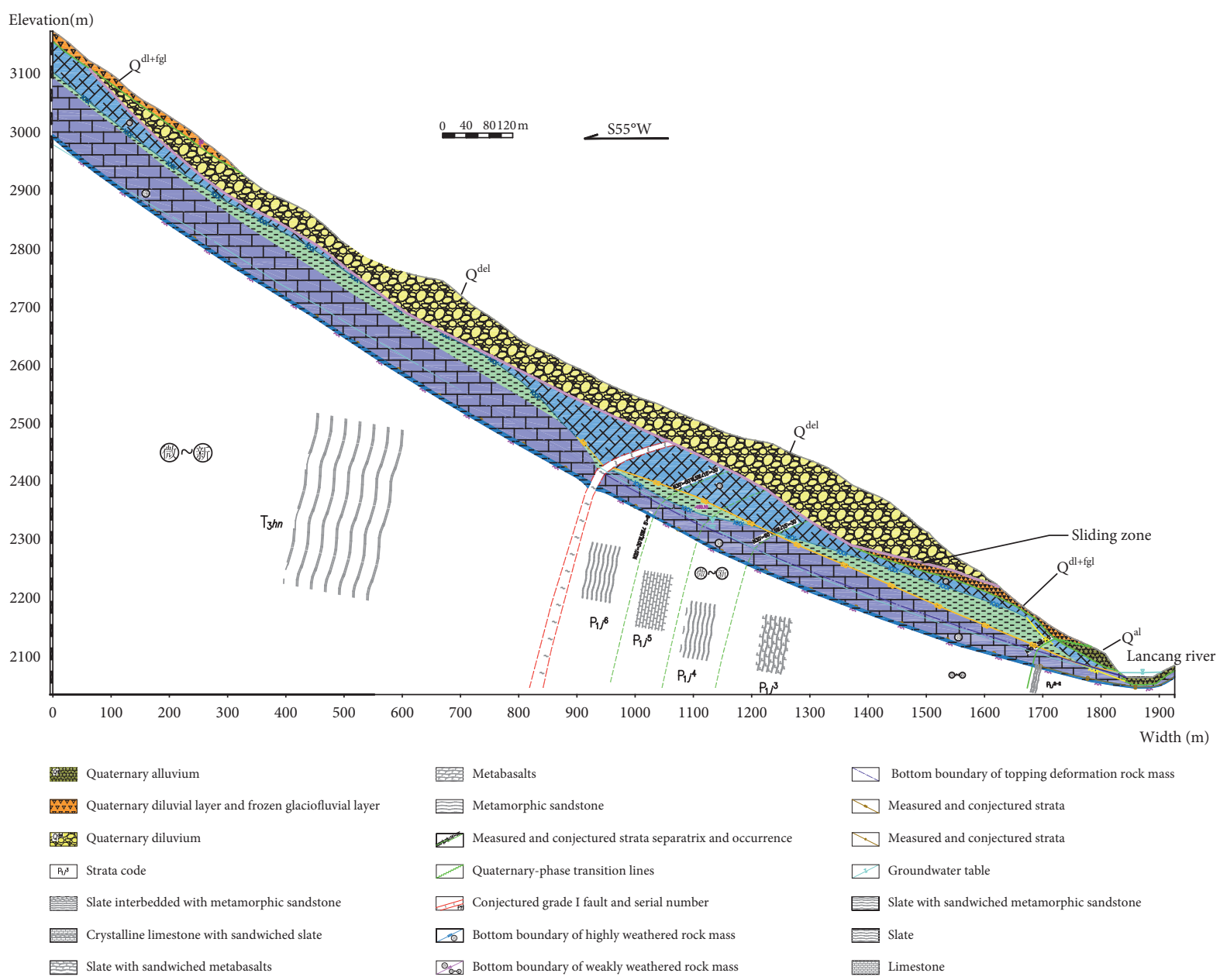

(b)

Figure 4: Engineering geologic profiles of the Zhenggang landslide. (a) Profile A-A' in zone I. (b) Profile B-B' in zone II.

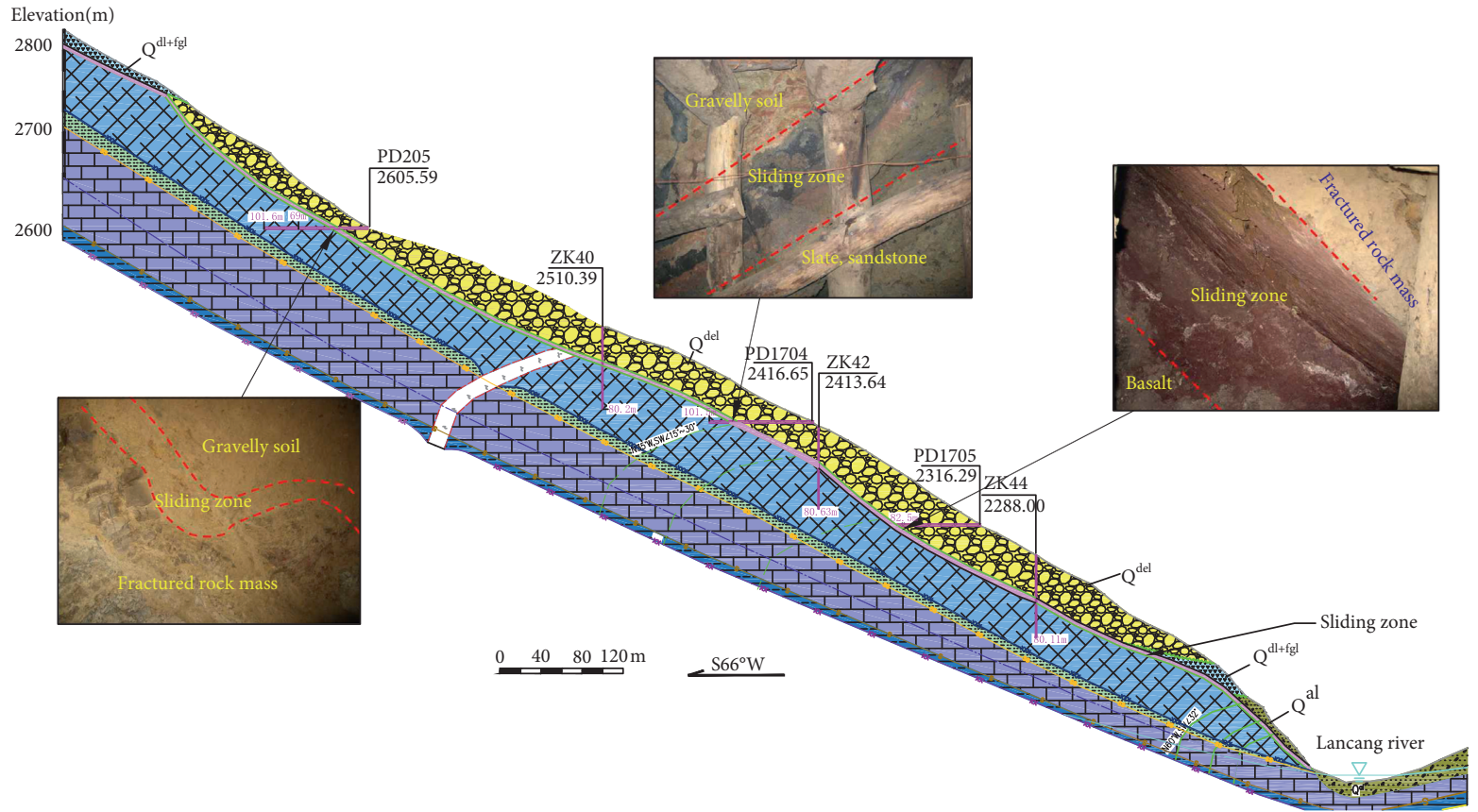

(a)

Figure 5: Continued. 


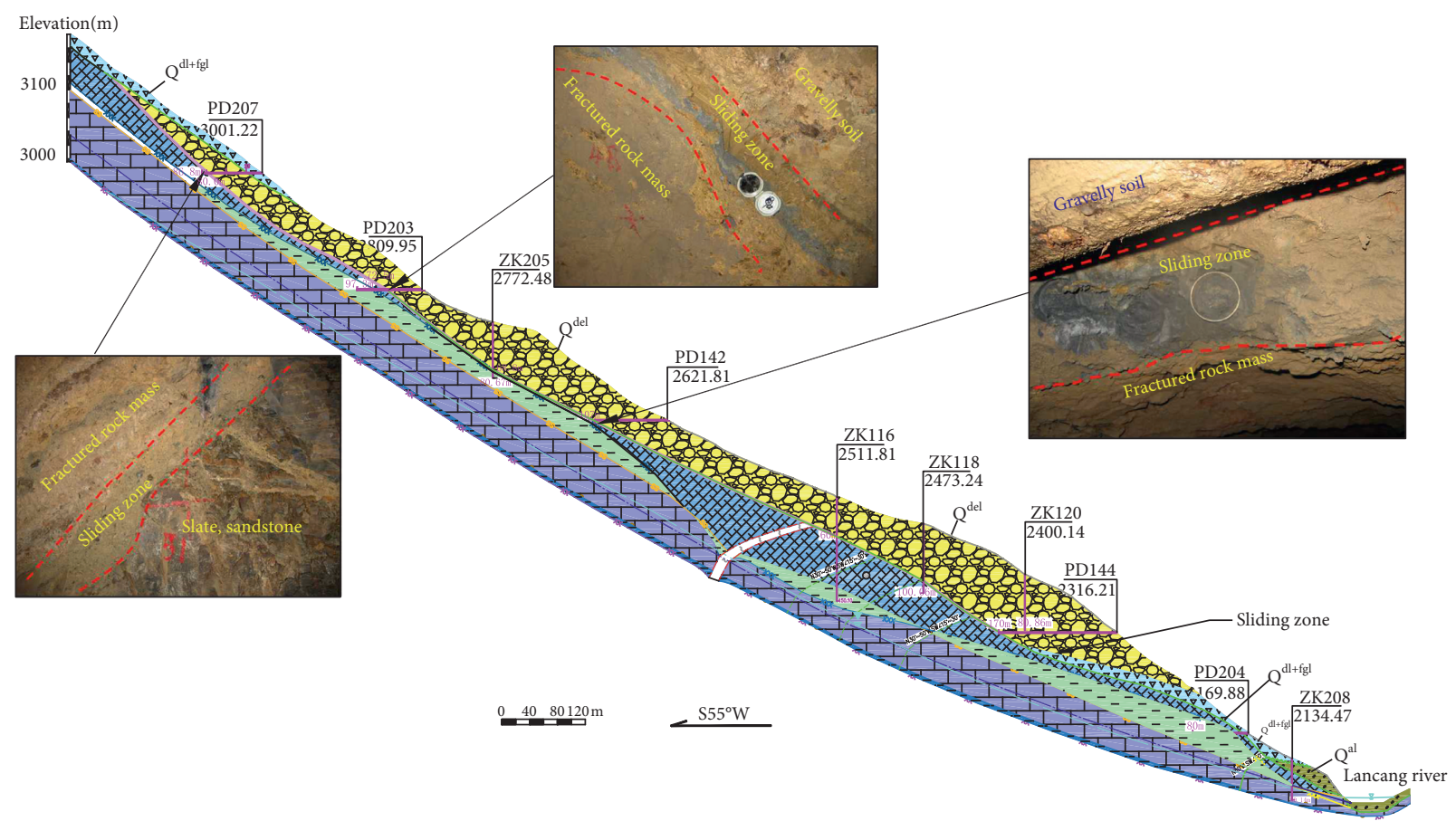

(b)

Figure 5: Characteristics of the sliding zone in the drill holes and exploratory adits. (a) Profile A-A' in zone I. (b) Profile B-B' in zone II.

TABLe 1: Limit water content and particle size distribution for soil samples collected at slip zone and landslide mass.

\begin{tabular}{|c|c|c|c|c|c|c|c|c|c|}
\hline \multirow{2}{*}{ Sample collected sites } & \multirow{2}{*}{ Gravity } & \multicolumn{3}{|c|}{ Limit water content (\%) } & \multicolumn{5}{|c|}{ Particle size distribution (\%) } \\
\hline & & Liquid limit & Plastic limit & Plasticity index & Gravel & Pebble & Sand & Silt & Clay \\
\hline Slip zone & 2.78 & 32.1 & 14.9 & 17.2 & 0.0 & 20.0 & 25.0 & 20.0 & 35.0 \\
\hline Landslide mass & 2.81 & 24.1 & 11.5 & 12.6 & 11.0 & 55.0 & 20.0 & 11.0 & 3.0 \\
\hline
\end{tabular}

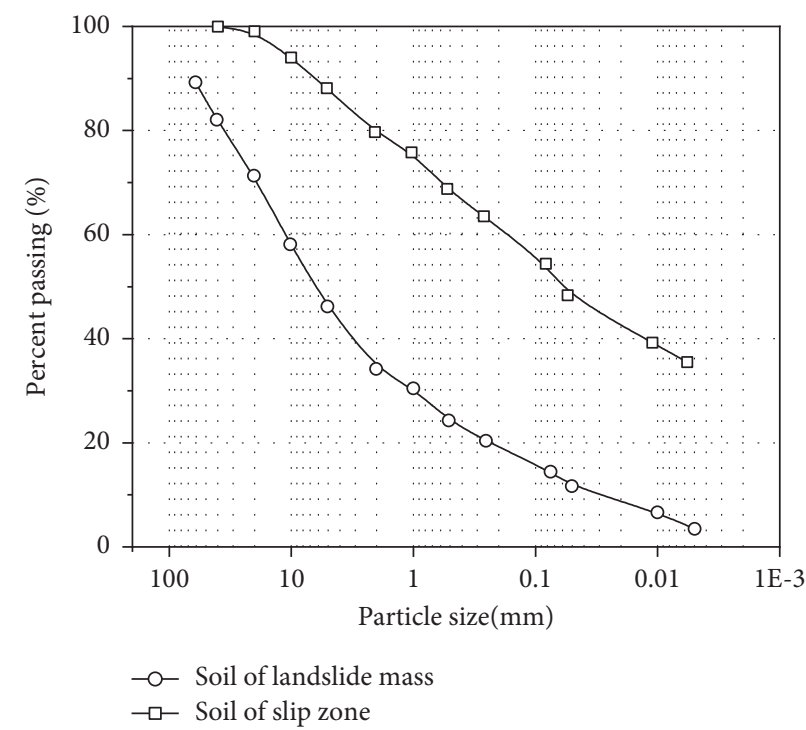

Figure 6: Particle size distribution for soil samples collected at landslide mass and slip zone. 


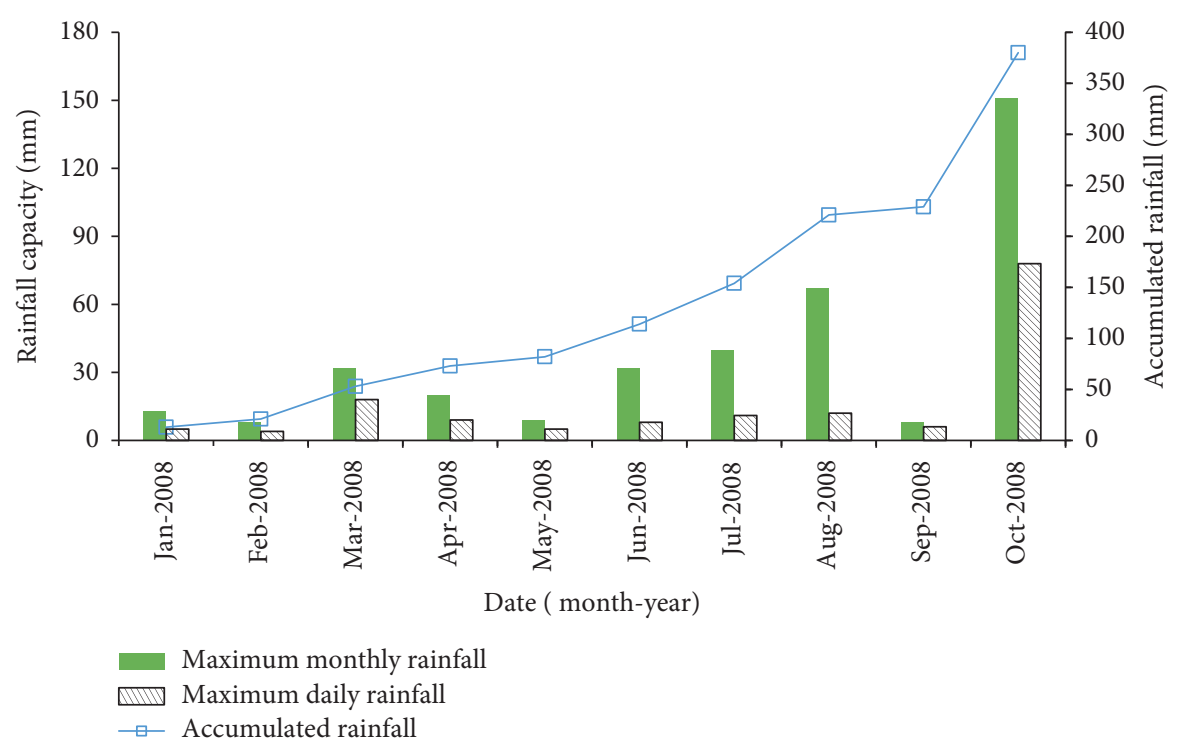

FIGURE 7: Rainfall recorded at the Liutongjiang Hydrologic Station before the landslide reactivation.

Hydrologic Station. During this period of continuous rainfall, a large creep deformation moving toward the Lancang River valley occurred on the Zhenggang landslide's slope. It has been shown that subslide zone I is a translational slide, and zone II is an uplift slide. Figure 8 shows the crack propagation and collapse characteristics of subslide zones I and II after the rainfall from October 20 to November 5, 2008.

As shown in Figure 8, in subslide zone I, deformational failure was observed at horizontal depths of 50-65 $\mathrm{m}$ in PD1704. Due to the creeping deformation of the landslide, we also observed that many of the vertical wood forepolings were fractured in their center, and some of the horizontal top wood forepolings were also broken (Figure 8(a)). The extension of tensional cracks occurred at the rear edges, usually with widths of $15-30 \mathrm{~cm}$, and these cracks were new and formed a 1-2 m wide tensioncollapse belt (Figure 8(b)). At EL.2200-2280 m, a shear dislocation of the slip zone occurred at a horizontal depth of $56 \mathrm{~m}$. Creep sliding was monitored during this period. Due to subsidence damage in the rear part, the integral displacement of the sliding mass resulted in a local slope failure at the front shear sliding mouth (Figure 8(c)). Simultaneously, newly developed longitudinal cracks intercalated with transverse cracks at the rear edges formed an arc-shaped collapse sliding surface on the plane, which was evidenced by intensive tension cracks at 2130-2150 m (Figure 8(d)). Due to the good air fronting conditions and steep terrain, steep tensile cracks easily formed within a small local range on the surface of the accumulation body. In addition, a potential slip surface was formed with a relatively weak layer inside the accumulation body, which gradually slid toward the bottom of the trench under the action of adverse loads (Figures 8(e) and 8(f)). According to the field investigation, this mode is mainly concentrated on both sides of the Zhenggang gully. The main reason for this is that the lateral constraint on the accumulation body in this area was lifted due to the cutting effect of the Zhenggang gully.

In subslide zone II, tension-collapse belts and several fractures were found at EL.2250 $\mathrm{m}$ and $2400 \mathrm{~m}$ (Figure 8(g)). Tension cracks in the rear portion of subslide zone II produced a large amount of deformation, resulting in the formation of a $2-5 \mathrm{~m}$ wide and 3-5 $\mathrm{m}$ high stagger platform in front of the cracks. A large number of shear cracks occurred in the middle and lower parts, especially inside Yagong gully. In this area, a large deformation bent a steel water pipe and destroyed the concrete pier containing the steel water pipe (Figures $8(\mathrm{~h})$ and $8(\mathrm{i})$ ). A large transverse crack (1577 $\mathrm{m}$ long) ran completely through the middle and rear parts of the landslide mass at 2270-2710 m (Figure 8(j)).

Through comparison and analysis of the crack propagation and collapse characteristics of zone I and zone II, it is preliminarily concluded that zone II is more stable than zone I. Heavy rainfall is the main factor affecting the deformation and failure of the landslide. The collapse and disintegration of the leading edge and adjacent side of zone I may be controlled by the Zhenggang gully. The emergence of a tensile fracture in the middle provides a favorable channel for the infiltration of surface water, which will expand the fracture and accelerate the creep of the rock and soil mass of the landslide, and then overall sliding will occur. At present, the deformation and failure signs in the middle and front parts of zone I mainly appeared after the heavy rainfall from October 20 to November 5, 2008, and the deformation intensified after the recent rainfall and snowfall in February 2009. With the local destruction of the front part and the expansion of the cracks in the middle of the landslide body, the sliding surface will become connected, which may eventually lead to overall sliding. Therefore, it is necessary to deeply analyze the deformation evolution law of the landslide body under rainfall conditions and to determine the influence of rainfall on the resurrection of the deformation of the landslide. 


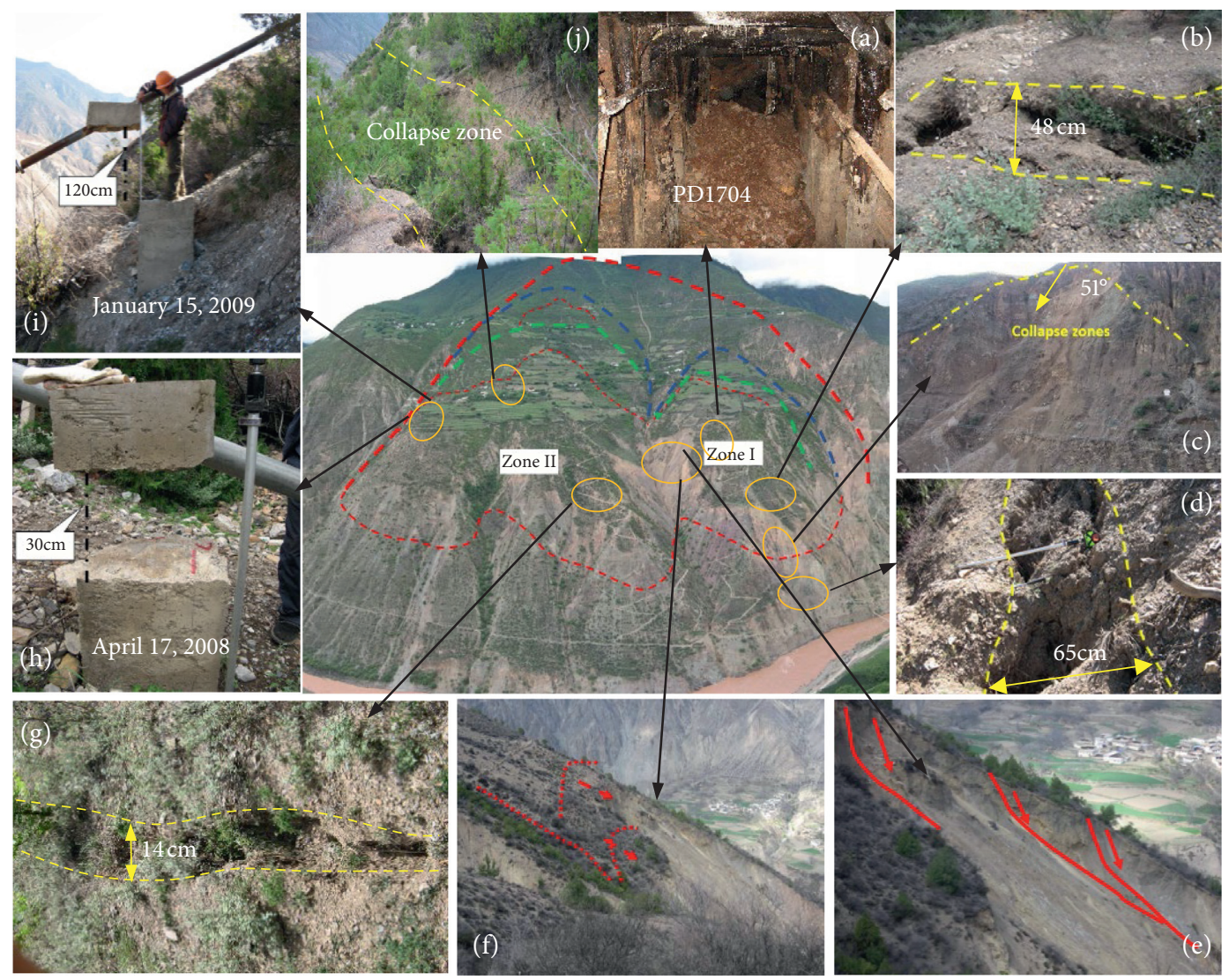

FIGURE 8: Crack propagation and collapse characteristics of subslide zones I and II. (a) Soil collapse and wood forepoling damage in PD1704. (b) A tensional crack (Apr. 2009). (c) Shear sliding outlet with a local collapse failure in the front part of the landslide mass (Apr. 2009). (d) A tension-collapse belt at the rear edges of EL 2130-2150 m (Jan. 2009). (e) Instability model of gradual disintegration on the left side of the Zhenggang gully. (f) Instability zone of gradual disintegration on the left side of the Zhenggang gully. (g) Several groups of medium fractures in the front of zone II, with elevations of 2250-2400 m. ((h) and (i)) Failure of a concrete pier photographed on April 17, 2008, and January 15, 2009, respectively. (j) Tension-collapse belt at the rear part of EL $2650 \mathrm{~m}$ (Jan. 2009).

\section{Discussion}

4.1. Analysis of the Geological Evolution of the Landslide. The field investigation and geological analysis indicated that the Zhenggang landslide evolved during multiple geological periods, and it experienced a series of geological, environmental, geomorphological, and mechanical changes that consisted of the four following continuous phases: (1) the early stable phase that was characterized by a wider valley and shallow incision; (2) the bending and toppling failure phase during which weathered cataclastic stones and soils were moved by a glacier onto the third-order terrace to form $\mathrm{Q}^{\mathrm{fgl}}$; (3) the phase in which the upper rock mass toppled down and the middle and lower rock mass experienced compression-shear failure; and (4) the ancient landslide formation phase during which many failure surfaces merged together and induced landslide dams about 7,500 years ago.

Postrenovation and evolution phase of the slide deposits (Figure 4) is the period during which the movement of the landslide mass resulted in the descent of the gravitational center and potential energy dissipation. The landslide mass was gradually consolidated and reinforced itself in terms of strength after the water drained away. Afterward, the landslide appeared to be relatively stable. The river water flowed, the deposits were transported, and the riverbed was subsequently eroded downward to form the present valley's geomorphology. During this period, the gravelly soils were composed of landslide deposits $\left(\mathrm{Q}^{\mathrm{del}}\right)$, and glacier fluvial deposits $\left(\mathrm{Q}^{\mathrm{fgl}}\right)$ formed and were left on the shallow slope.

4.2. Analysis of Rainfall-Induced Landslide Resurrection. According to the analysis results of geological characteristics, crack propagation, and collapse characteristics of Zhenggang landslide, it is found that zone I is inferior to zone II in stability, and rainfall infiltration is the main factor that induced the reactivation of ancient landslide deposits. In order to reveal the influence of rainfall on the stability of landslide deposits, the A-A' section in zone I was selected for the seepage stability analysis under rainfall conditions. The finite element method was used to analyze the seepage flow of landslide deposits under rainfall condition. Rainfall condition was simulated according to the actual rainfall data from October 20 to November 5, 2008. The rainfall duration was 72 hours, in which the rainfall on the first 10 hours was $100 \mathrm{~mm}$, and the total rainfall for the remaining 62 hours was $51 \mathrm{~mm}$. Through numerical calculation, the seepage characteristics of landslide accumulation body under rainfall conditions are shown in Figure 9. 


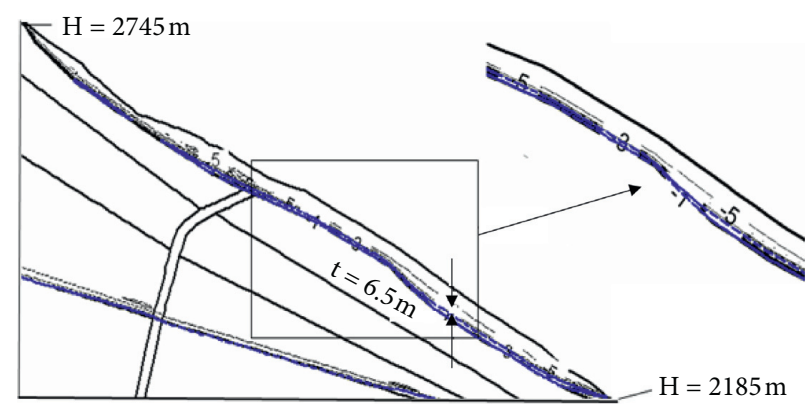

Figure 9: Pressure head distribution of Profile A-A' in zone I in four days after rain (unit: $\mathrm{m}$ ).

TABLE 2: Computational parameters for strata of Zhenggang landslide.

\begin{tabular}{lcccc}
\hline Stratum & & \multicolumn{2}{c}{ Computational parameters } \\
& Friction angle $\left(^{\circ}\right)$ & Cohesion $(\mathrm{kPa})$ & Natural unit weight $\left(\mathrm{kN} / \mathrm{m}^{3}\right)$ & Saturated unit weight $\left(\mathrm{kN} / \mathrm{m}^{3}\right)$ \\
\hline Landslide mass & 30.0 & 40.0 & 21.5 & 23.0 \\
Slip zone & 27.9 & 20.0 & 20.5 & 22.0 \\
Bedrock & 34.0 & 180.0 & 23.0 & 23.5 \\
\hline
\end{tabular}

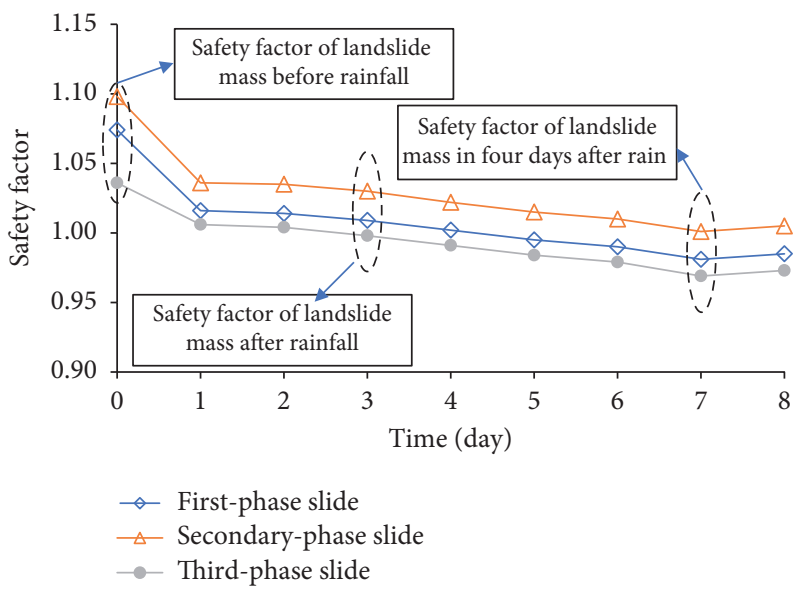

FIgURE 10: Changes of safety factor of profile A-A' in zone I with time under rainfall conditions.

As shown in Figure 9, after 10 hours of heavy rain, the negative pressure near the sliding zone increased, the sliding zone soil had not yet reached saturation state, and there was no stagnant water phenomenon in the sliding zone. After two days of rain, the stagnant water layer with the thickness of about $0.5 \mathrm{~m}$ first appeared on the sliding zone of EL. 2200-2206 m. After three days of rain, the range of stagnant water layer expanded to the elevation of EL. 2386-2547 m and EL. 2198-2323 m, with an average thickness of $0.5 \mathrm{~m}$. In the four days after rain, the stagnant water layer was almost distributed at the elevation of EL.2185-2656 m. The thickness of stagnant water layer was about $6 \mathrm{~m}$ in the low-lying areas and there was the water overflow near the shear outlet.

On the basis of seepage calculation, the limit equilibrium stability of landslide stability was calculated. The computational parameters are given in Table 2 . The variation rule of landslide safety factor with time under rainfall condition is shown in Figure 10. The results showed that the safety factor of slope decreases gradually with the increase of rainfall duration. After the rain stopped, the slope safety factor continued to decrease and reached the lowest level in four days after rain. This was mainly because rainfall infiltration was the main factor to induce the revival of ancient landslide. When the cracks developed on the slope surface, the rainfall rapidly infiltrated along the cracks, which caused the increase in the gravity of sliding mass, weakening the strength of sliding mass and sliding zone, as well as the increase in the pore water pressure, thus reducing the overall stability of landslide deposits. Therefore, it was necessary to strengthen the risk assessment and reliability of Zhenggang landslide under the condition of rainfall infiltration.

4.3. Suggestions for Landslide Treatment. The Zhenggang landslide has been stable in its natural state from the ancient to the tertiary period of movement. In this natural state, landslide movement has a low probability of occurrence, but the probability greatly increases when the landslide is in a 
rainfall saturated state. To reduce the risk of landslides occurring, the local residents living near the landslide mass should be relocated and measures should be taken to increase the slope's stability.

(1) The poor drainage conditions caused by the low permeability of the slip zone soil result in perched water remaining at the bottom of the sliding surfaces, which reduces the landslide's stability. The construction of surface drains and drainage tunnels above $2600 \mathrm{~m}$ is strongly recommended. The existing exploratory adits in the landslide mass would be helpful in this regard.

(2) During the excavation of the spillway and diversion tunnels, subslide zone I must be reinforced. On the slope, bench excavation is recommended. In the middle and front parts of the landslide, the installation of antislide piles is strongly recommended as an optimal treatment solution.

(3) Rainfall is a major factor affecting the stability of the Zhenggang landslide deposits. Directing the surface water and groundwater away from the landslide would increase the stability of the Zhenggang landslide. Slope surface and groundwater draining solutions should be designed according to the landslide's topography to maximize slope stabilization.

\section{Conclusions}

(1) Geological surveys and stability analysis revealed that the Zhenggang landslide is currently relatively stable and is not sliding, but it remains a potential threat to the Gushui Hydropower Project and could possibly create a landslide-dammed lake.

(2) The Zhenggang landslide has experienced ancient, secondary, and third phases of sliding. The thirdphase sliding was primarily induced by continuous rainfall from October 20 to November 5, 2008, which indicates that groundwater aggravated sliding and deformation. The upper loose gravelly soil of the landslide mass is prone to seepage, while the lower fine-grained clay is favorable for the retention of perched water at the bottom of the slip zone. These factors could reduce the stability of the landslide. Therefore, the groundwater and surface water should be drained away from the landslide mass.

(3) The landslide is split by the Zhenggang gully into two subslide zones with different types of movement. Subslide zone I is a translational slide, while subslide zone II is an uplift slide. There are several shear slide outlets in the front part of zone I, where localized small collapses have occurred. Many large transverse cracks with widths of $15-30 \mathrm{~cm}$ were observed on the slope, most of which were caused by tensile stress. Obvious interior deformational failure has occurred and was observed in the exploratory adits.
(4) Rainfall infiltration is the main factor that induced the reactivation of ancient landslide deposits. When the cracks developed on the slope surface, the rainfall rapidly infiltrated along the cracks, which caused the increase in the gravity of sliding mass, weakening the strength of landslide mass and sliding zone, as well as the increase in the pore water pressure, thus reducing the overall stability of landslide deposits.

(5) It is suggested that the potential hazards posed by the Zhenggang landslide deposits be mitigated by stabilizing the slopes. This may involve placing antisliding piles on the slope, draining water from the slope, and reducing the local construction loads on the slope.

\section{Data Availability}

The raw/processed data required to reproduce the findings in this paper cannot be shared at this time as the data also forms part of an ongoing study.

\section{Conflicts of Interest}

The authors declare that they have no conflicts of interest.

\section{Authors' Contributions}

Rubin Wang contributed to the conception of the study. Rubin Wang, Yu Ning, Wenyuan Wang, and Jianfu Qin performed the geological characteristics analysis; Rubin Wang and Kun Zhang performed the analysis of the crack propagation and collapse characteristics and the discussion. Weiya Xu performed the critical revision of the manuscript for important intellectual content. Rubin Wang and Yu Ning wrote the original paper. Rubin Wang and Kun Zhang wrote the revised paper.

\section{Acknowledgments}

This work was supported by the National Key Research and Development Program of China (no. 2017YFC1501100), the National Natural Science Foundation of China (no. 51939004), and the Fundamental Research Funds for the Central Universities (no. B200204008). The authors are deeply indebted and owe their thanks to PowerChina Kunming Engineering Corporation Limited for assistance in the collection of engineering geological exploration data.

\section{References}

[1] G. W. Lin, H. Chen, D. N. Petley, M. J. Horng, S. J. Wu, and B. Chuang, "Impact of rainstorm-triggered landslides on high turbidity in a mountain reservoir," Engineering Geology, vol. 117, no. 1-2, pp. 97-103, 2011.

[2] W.-Z. Guo, L. Luo, W.-L. Wang et al., "Sensitivity of rainstorm-triggered shallow mass movements on gully slopes to topographical factors on the Chinese Loess Plateau," Geomorphology, vol. 337, pp. 69-78, 2019.

[3] T. Y. Duman, "The largest landslide dam in Turkey: tortum landslide," Engineering Geology, vol. 104, no. 1-2, pp. 66-79, 2009. 
[4] C. T. Sfanelli, N. Casagli, and F. Catani, "Landslide damming hazard susceptibility maps: a new GIS-based procedure for risk management," Landslides, vol. 17, no. 7, pp. 1635-1648, 2020.

[5] M. Pastor, I. Herreros, J. A. Fernández Merodo et al., "Modelling of fast catastrophic landslides and impulse waves induced by them in fjords, lakes and reservoirs," Engineering Geology, vol. 109, no. 1-2, pp. 124-134, 2009.

[6] F. C. Dai, C. F. Lee, J. H. Deng, and L. G. Tham, "The 1786 earthquake-triggered landslide dam and subsequent dambreak flood on the Dadu River, southwestern China," Geomorphology, vol. 65, no. 3-4, pp. 205-221, 2005.

[7] S. Bosa and M. Petti, "Shallow water numerical model of the wave generated by the Vajont landslide," Environmental Modelling \& Software, vol. 26, no. 4, pp. 406-418, 2011.

[8] I. G. Fourniadis, J. G. Liu, and P. J. Mason, "Landslide hazard assessment in the Three Gorges area, China, using ASTER imagery: wushan-Badong," Geomorphology, vol. 84, no. 1-2, pp. 126-144, 2007.

[9] R. Q. Huang, "Some catastrophic landslides since the twentieth century in the southwest of China," Landslides, vol. 6, no. 1, pp. 69-81, 2009.

[10] H. Tang, J. Wasowski, and C. H. Juang, "Geohazards in the three gorges reservoir area, China - lessons learned from decades of research," Engineering Geology, vol. 261, p. 105267, 2019.

[11] O. Korup, "Recent research on landslide dams - a literature review with special attention to New Zealand," Progress in Physical Geography: Earth and Environment, vol. 26, no. 2, pp. 206-235, 2002.

[12] O. Korup, "Geomorphometric characteristics of New Zealand landslide dams," Engineering Geology, vol. 73, no. 1-2, pp. 3-35, 2004.

[13] O. Korup and F. Tweed, "Ice, moraine, and landslide dams in mountainous terrain," Quaternary Science Reviews, vol. 26, no. 25-28, pp. 3406-3422, 2007.

[14] J. W. Zhou, W. Y. Xu, X. G. Yang, C. Shi, and Z. H. Yang, "The 28 October 1996 landslide and analysis of the stability of the current huashiban slope at the liangjiaren hydropower station, southwest China," Engineering Geology, vol. 114, no. 1-2, pp. 45-56, 2010.

[15] Y. Wan and J. Kwong, "Shear strength of soils containing amorphous clay-size materials in a slow-moving landslide," Engineering Geology, vol. 65, no. 4, pp. 293-303, 2002.

[16] B. P. Wen, A. Aydin, N. S. Duzgoren-Aydin, Y. R. Li, H. Y. Chen, and S. D. Xiao, "Residual strength of slip zones of large landslides in the Three Gorges area, China," Engineering Geology, vol. 93, no. 3-4, pp. 82-98, 2007.

[17] S. Bernander, A. Kullingsjo, A. S. Gylland et al., "Downhill progressive landslides in long natural slopes: triggering agents and landslide phases modeled with a finite difference method," Canadian Geotechnical Journal, vol. 53, no. 10, pp. 1565-1582, 2016.

[18] H. J. Chai, H. C. Chao, Z. Y. Zhang, and Z. W. Xu, "The distribution, causes and effects of damming landslides in China," Journal of Chengdu University of Technology, vol. 27, no. 3, pp. 302-307, 2000.

[19] R. Huang, "Mechanisms of large-scale landslides in China," Bulletin of Engineering Geology and the Environment, vol. 71, no. 1, pp. 161-170, 2012.

[20] Q. L. Zeng, Z. Q. Yue, Z. F. Yang, and X. J. Zhang, "A case study of long-term field performance of check-dams in mitigation of soil erosion in Jiangjia stream, China," Environmental Geology, vol. 58, no. 4, pp. 897-911, 2009. 